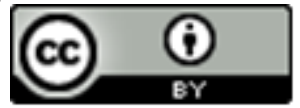

\title{
ESPAÇO, GÊNERO E RAÇA: OS MOVIMENTOS SOCIAIS E OS DESAFIOS CONTEMPORÂNEOS
}

\author{
Antonia dos Santos Garcia ${ }^{1}$
}

\begin{abstract}
Que no hay patria en que pueda tener el hombre más orgullo que en nuestras dolorosas repúblicas americanas
\end{abstract}

(José Marti, 1891)

"Por um mundo onde sejamos socialmente iguais, humanamente diferentes e totalmente livres"

(Rosa de Luxemburgo) Negritude: "O despertar de dignidade, rejeição da opressão, lutar contra a desigualdade"

(Aimé Cesaire)

Resumo: Neste artigo vamos refletir sobre as origens e histórias comuns da América Latina, Caribe e África considerando-se que o sistema colonial escravista moldou nossas sociedades e cidades, e o Brasil nesse contexto. A construção eurocêntrica das sociedades e cidades no chamado Novo Mundo, tem seu tripé no colonialismo-escravismo, patriarcalismo-racismo e no mercantilismo-capitalismo, que também produziu modelos explicativos que alimentam até hoje uma perversa engrenagem teórico-ideológicapolítica que favorece a reprodução de desigualdades e a perpetuação no poder dos grupos brancos hegemônicos. Enfrentar a metodologia da omissão na perspectiva da raça, gênero, classe e espaço nesses continentes é crucial para projetos de emancipação humana e superação do sistema de opressão universal.

Palavras-chave: Eurocentrismo; Capitalismo; Gênero; Raça, Espaço

\section{SPACE, GENDER AND RACE: SOCIAL MOVEMENTS AND CONTEMPORARY CHALLENGES}

\begin{abstract}
In this article we will reflect on the origins and common histories of Latin America, the Caribbean and Africa considering that the slave colonial system shaped our societies and cities, and Brazil in this context. The Eurocentric construction of societies and cities in the so-called New World has its tripod in colonialism-enslavement,

\footnotetext{
${ }^{1}$ Socióloga e mestre em Geografia pela UFBA, doutora em urbanismo pela Universidade Federal do Rio de Janeiro (UFRJ), pós-doutora e pesquisadora associada/NEIM/PPGNEIM/FFCH/UFBA e coordenadora do OBSERVATÓRIO LUIZA MAHIN/Grupo Espaço Livre/UFBA/CNPq, Centro da Mulher Baiana (CEM) e fundadora e ex-diretora executiva da Federação das Associações de Bairros de Salvador-FABS. E-mail: antoniagarcia @ terra.com.br ; ORCID: https://orcid.org/0000-0003-3536-8705
} 
patriarchalism-racism and mercantilism-capitalism, which also produced explanatory models that feed to this day a perverse theoretical-ideological-political gear that favors the reproduction of inequalities and the perpetuation in the power of hegemonic white groups. Facing the methodology of omission from the perspective of race, gender, class and space in these continents is crucial for projects of human emancipation and overcoming the system of universal oppression.

Keywords: Eurocentrism; Capitalism; Gender; Race, Space

\section{ESPACIO, GÉNERO Y RAZA: MOVIMIENTOS SOCIALES Y DESAFÍOS CONTEMPORÁNEOS}

Resumen: En este artículo reflexionaremos sobre los orígenes e historias comunes de América Latina, el Caribe y Africa considerando que el sistema colonial esclavo dio forma a nuestras sociedades y ciudades, y a Brasil en este contexto. La construcción eurocéntrica de sociedades y ciudades en el llamado Nuevo Mundo tiene su trípode en el colonialismo-esclavitud, patriarcalismo-racismo y mercantilismo-capitalismo, que también produjo modelos explicativos que alimentan hasta el día de hoy un perverso equipo teórico-ideológico-político que favorece la reproducción de las desigualdades y la perpetuación del poder de los grupos blancos hegemónicos. Enfrentar la metodología de omisión desde la perspectiva de la raza, el género, la clase y el espacio en estos continentes es crucial para los proyectos de emancipación humana y la superación del sistema de opresión universal.

Palabras clave: Eurocentrismo; Capitalismo; Género; Carrera, Espacio

\section{ESPACE, GENRE ET COURSE: MOUVEMENTS SOCIAUX ET DÉFIS CONTEMPORAINS}

Résumé : Dans cet article, nous réfléchirons sur les origines et les histoires communes de l'Amérique latine, des Caraïbes et de l'Afrique, considérant que le système colonial des esclaves a façonné nos sociétés et nos villes, et le Brésil dans ce contexte. La construction eurocentrique des sociétés et des villes dans le soi-disant Nouveau Monde a son trépied dans le colonialisme-esclavage, le patriarcat-racisme et le mercantilisme-capitalisme, qui a également produit des modèles explicatifs qui alimentent à ce jour un pervers l'engrenage théorique-idéologique-politique qui favorise la reproduction des inégalités et la perpétuation du pouvoir des groupes blancs hégémoniques. Face à la méthodologie d'omission du point de vue de la race, du sexe, de la classe et de l'espace sur ces continents est crucial pour les projets d'émancipation humaine et de surmonter le système d'oppression universelle.

Mots-clés: Eurocentrisme; Le capitalisme; Le genre; Course, Espace

\section{INTRODUÇÃO}

Este artigo parte das reflexões realizadas durante o seminário da CLACSO - 
Conselho Latino Americano de Ciências Sociais em $2019^{2}$ e artigo apresentado sob o título Os Movimentos Sociais e os Desafios Contemporâneos: Negritude, Capitalismo e Escravidão. Pensar o Brasil na perspectiva da raça, gênero, espaço no contexto na América Latina, Caribe e África é fundamental para projetos de emancipação humana. Como militante dos movimentos urbanos e de mulheres negras da periferia de Salvador, primeira cidade e capital do Brasil colonial, cidade mais negra demográfica e culturalmente fora da África busco compreender as raízes das desigualdades sociorraciais e de gênero ${ }^{3}$, de classe social no espaço. Em nossas pesquisas temos buscado a interseccionalidade destas categorias e o espaço urbano e creio que precisamos realizar mais pesquisas e reflexões sobre as origens dos nossos países a partir de uma matriz colonialista e escravista visando a desconstrução desses paradigmas, dessas teorias opressivas. Entender o Brasil, também de maioria negra no contexto da América Latina, Caribe e África é crucial considerando-se que o sistema colonial escravista moldou nossas sociedades e durou mais de três séculos no Brasil (um pouco menos na maioria dos países colonizados). Foi o país que recebeu o maior número de escravizados e o último a se libertar do sanguinário sistema escravocrata que produziu o maior genocídio da Humanidade, durante os séculos de escravidão e na abolição inacabada como mostram vários estudos.

A escravidão aberta ou disfarçada de índios e índias, negros e negras na encomienda, hacienda, plantation, engenho, fazenda e outras modalidades de organização social e técnicas das relações de produção e das forças produtivas no chamado Novo Mundo, embora contraditório com o que ocorria na Europa onde se expandia a manufatura e depois a grande indústria generalizando-se o trabalho livre (IANNI, 1988, p.16), forjou nossas sociedades cujas consequências sofremos até hoje. O motor desse processo mais amplo era o capital comercial, que subordinava a produção de mercadorias na Europa e nas colônias do chamado Novo Mundo e em outros continentes. Em

\footnotetext{
${ }^{2}$ Seminário 1905 - Raza/negritud y humanidad. Traducciones interculturales entre América Latina, el Caribe y África me coloquei- o objetivo de ampliar meus conhecimentos sobre América Latina, Caribe e África, buscando interlocuções pouco comuns nos estudos brasileiros sobre nossa origem, história comum, nossas cidades, e parte deste artigo resulta também do artigo apresentado.

${ }^{3}$ A relevância e atualidade da questão de gênero está na pesquisa no Programa das Nações Unidas para o Desenvolvimento (PNUD) que analisou 75 países que representam $80 \%$ da população global. Nesta pesquisa se constata que que nove a cada dez pessoas, inclusive mulheres, têm preconceito de gênero. E o Brasil é um dos piores países da América Latina, chegando a 89,50\%. "Em torno de $90 \%$ da população mundial, sem importar o sexo, têm preconceito contra as mulheres".
} 
decorrência, expandia-se o capital comercial, criavam-se as condições estruturais no seio das quais iria desenvolver-se o capitalismo, afirma o autor.

Para Marx, o tráfico negreiro constituía-se de um método de acumulação primitiva comandado pela Inglaterra, na medida em que: "Liverpool empregava 15 navios no tráfico negreiro, em 1730; 58, em 1751; 74, em 1760; 96, em 1770, e 132, 1792 e a indústria algodoeira têxtil ao introduzir a escravidão infantil na Inglaterra impulsionava ao mesmo tempo a escravidão negra dos Estados Unidos que, antes era mais ou menos patriarcal, num sistema de exploração mercantil. A escravidão dissimulada dos assalariados na Europa precisava fundamentar-se na escravatura sem disfarces, no Novo Mundo (MARX, apud IANNI, 1988, p.16).

Para (STEIN apud IANNI, 1988, p.60), em 1853, "ao afirmar que a escravidão não atrasou a industrialização, a comissão de preços admitia que a maioria era mão de obra escrava". Aliás, em meados do século XIX Marx já havia assinalado o caráter 'anômalo' e 'formalmente burguês' da formação social nas Américas e Antilhas (IANNI, 1988):

A escravidão dos negros - uma escravidão puramente industrial - que desaparece de um momento para o outro e é incompatível com o desenvolvimento da sociedade burguesa, pressupõe a existência de tal sociedade: se junto a essa escravidão não existissem outros estados livres, com trabalho assalariado, todas as condições sociais nos estados escravistas assumiriam formas pre-civilizadas (MARX apud IANNI, 1988, p.33).

Entre os séculos XVI e XIX a Europa impôs o comércio triangular entre os continentes: África, Europa e Américas (do Norte, do Sul e Central), cujo principal elemento foi o tráfico negreiro, com o aprisionamento dos povos africanos, forma de exploração do ser negro que fizeram do mundo atlântico um negócio bastante lucrativo. A expansão do capitalismo mercantil cria, mantém e desenvolve contradições representadas pela coexistência do trabalho escravo e trabalho livre no âmbito do mercantilismo e as formações sociais escravistas tornaram-se organizações políticoeconômicas altamente articuladas com seus centros de poder, independentemente dos graus e maneiras de vinculação e dependência das colônias em face da metrópole. E assim, desde o século XVI, quando se iniciou o tráfico de africanos e africanas "entre os grupos escravizados as mulheres eram cerca de $20 \%$ inferior ao número de homens transportados" (SCHUMAHER, 2007, p.16) para o chamado Novo Mundo, até o século 
XIX, quando cessou esse tráfico e terminou formalmente a escravatura, teriam sido trazidos da África cerca de 9.500.000 negros e cerca de 4 milhões para o Brasil (IANNI, 1978, p.19), que construíram nossos países, nossas cidades, nossas riquezas apropriadas pelo colonizador desde então.

Como dito anteriormente, europeus e suas metrópoles como Portugal, Espanha, Inglaterra e França garantiram através do tráfico negreiro e o trabalho forçado de indígenas, negros e negras, o funcionamento do próprio sistema econômico mercantilista para produzir excedente e riqueza de suas metrópoles estabelecendo as bases do desenvolvimento capitalista com relações de subordinação e hierarquias que forjaram nossas sociedades como mostra a figura 1, abaixo.

Como periferia do capitalismo hegemônico, o desenvolvimento do modo de produção capitalista no chamado Novo Mundo, foi mais lento, embora a industrialização tivesse se iniciado na segunda metade do século XIX, ainda sob o escravismo nas nossas sociedades e sob a liderança da Inglaterra. Na Bahia, por exemplo, a fábrica têxtil instalada em Plataforma (1875), Salvador, Bahia, onde mulheres e crianças negras foram a mão de obra principal, conviveu-se simultaneamente com os dois sistemas.

A diáspora africana durante o tráfico transatlântico de escravizados e escravizadas, além da escravização de indígenas marca a extrema violência (torturas, morte e doenças) que os europeus impuseram a estes povos e sem paralelo na história. A magnitude dessa grande tragédia humana de pessoas oriundas da África, seu sofrimento, torturas, doenças, mortes, precisa ser objeto de denúncia permanente como ocorre com o Holocausto judeu e ações nos países afetados pelo longo processo de escravização e suas consequências na contemporaneidade onde racismo e sexismo entrelaçados continuam produzindo as desigualdades sociorraciais e de gênero e dando sustentação aos projetos de dominação social com extrema exploração. E como afirma Kabengele Munanga (2004), o racismo é indissociável da raça, mesmo quando não é proclama e os estudos atuais sobre gênero, sexismo precisam dar conta desta realidade vivida por milhões de pessoas no mundo. 
Figura 1 - Mercantilismo-Escravismo-Capitalismo

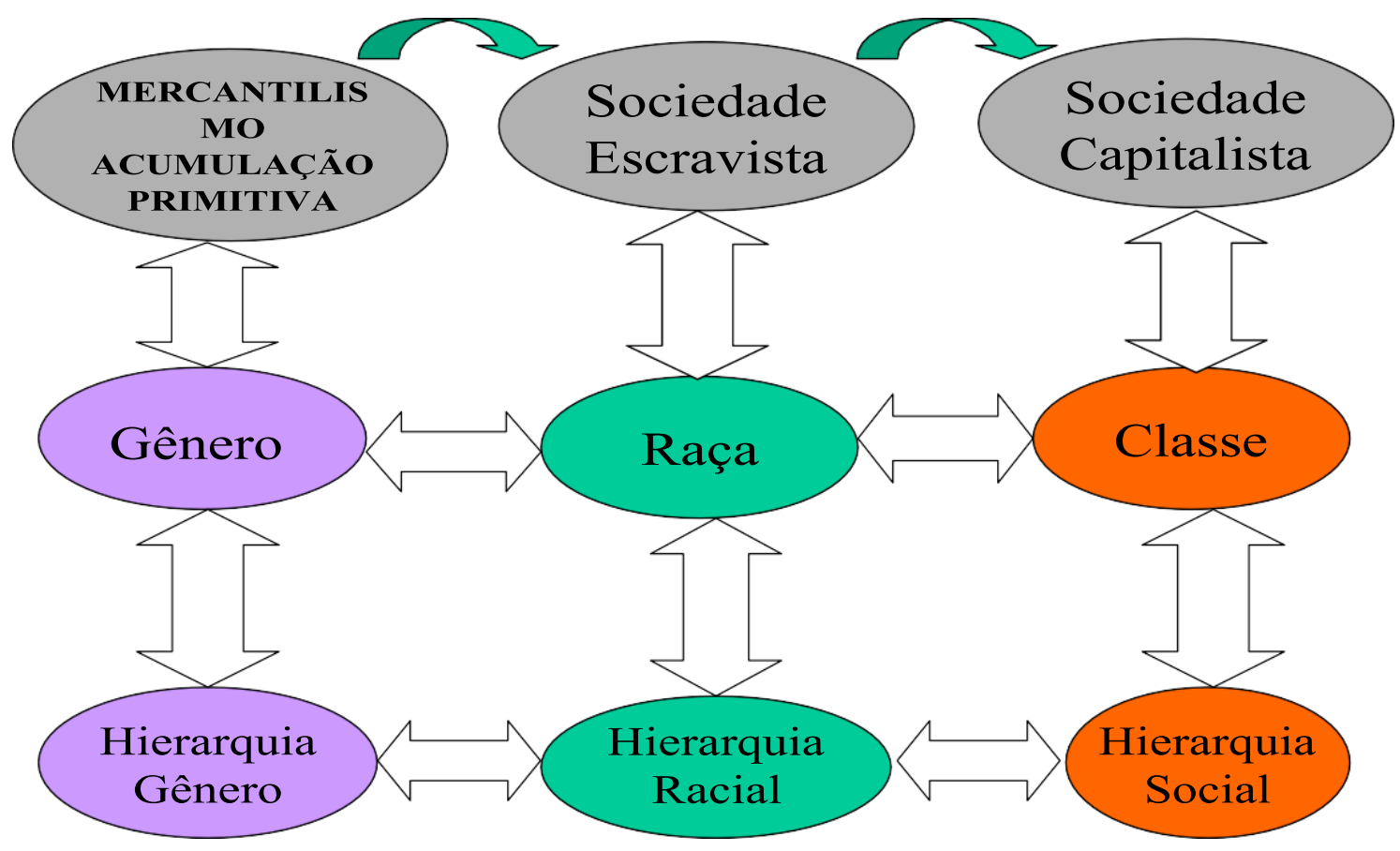

Fonte: Antonia Garcia - Elaboração própria - 2006

Portanto, o racismo e as teorias que o justificam como aponta Kabengele Munanga (2004), desde sua origem marca decisivamente a vida humana: uma religiosa e a outra pseudo científica: 1) o mito bíblico de Noé do qual resulta a primeira classificação religiosa da diversidade humana entre os três filhos de Noé ancestrais das três raças: Jafé (ancestral da raça branca), Sem (ancestral da raça amarela) e Cam (ancestral da raça negra). Os calvinistas baseiam-se nesse mito para justificar e legitimar o racismo antinegro; 2) se origina na classificação dita científica derivada da observação dos caracteres físicos (cor da pele, traços morfológicos (MUNANGA, 2004, p. 24-25).

O conceito de raça, construído socialmente deu sustentação ideológica ao processo de formação das nossas sociedades no chamado Novo Mundo. "É um conceito carregado de ideologia, pois como todas as ideologias ele esconde uma coisa não proclamada: a relação de poder e de dominação. O racismo como fenômeno híbrido e multifacetado, se combina com outros fenômenos, como o nacionalismo, o imperialismo, o etnocentrismo, o classismo, etc" (MUNANGA, 2004, p.27).

Corroborando com esta visão Aníbal Quijano afirma: 
$\mathrm{Na}$ América, a ideia de raça foi uma maneira de outorgar legitimidade às relações de dominação impostas pela conquista. A posterior constituição da Europa como nova id-entidade depois da América e a expansão do colonialismo europeu ao resto do mundo conduziram à elaboração da perspectiva eurocêntrica do conhecimento e com ela à elaboração teórica da ideia de raça como naturalização dessas relações coloniais de dominação entre europeus e não-europeus. Historicamente, isso significou uma nova maneira de legitimar as já antigas ideias e práticas de relações de superioridade/inferioridade entre dominantes e dominados. Desde então demonstrou ser o mais eficaz e durável instrumento de dominação social universal, pois dele passou a depender outro igualmente universal, no entanto mais antigo, o intersexual ou de gênero: os povos conquistados e dominados foram postos numa situação natural de inferioridade, e conseqüentemente também seus traços fenotípicos, bem como suas descobertas mentais e culturais. Desse modo, raça converteu-se no primeiro critério fundamental para a distribuição da população mundial nos níveis, lugares e papéis na estrutura de poder da nova sociedade. Em outras palavras, no modo básico de classificação social universal da população mundial (QUIJANO, 2005, p.118).

Comparando o Brasil com outros países da América Latina, Hasenbalg (1993, p.52) aponta dois eixos em torno dos quais se estabelecem as semelhanças entre o Brasil e as outras sociedades latino-americanas, forjadas no chamado Novo Mundo:

a) a concepção desenvolvida por elites políticas e intelectuais a respeito de seus próprios países inclui a caracterização através da harmonia e tolerância, e ausência de preconceito e discriminação racial (concepção que coexiste, em todos os casos, com a subordinação social ou virtual da desaparição dos descendentes de africanos); b) o embranquecimento, entendido tanto como projeto nacional implementado em políticas de povoamento e imigração, como em termos da obsessão em representar as respectivas sociedades como essencial, ou predominantemente brancas e de cultura hispânica, ou de forma mais inclusiva, europeia (HASENBALG, 1993, p.52).

De acordo com Carlos Eduardo Moreira (2006), "parte da história da escravidão atlântica foi vivenciada em paisagens urbanas ou semiurbanas" (MOREIRA, 2006, p.7) a exemplo de Buenos Aires, Caracas, Charlleston, Nova Orleans, Nova York, Havana, Recife, Rio de Janeiro, Salvador entre outras. As estratégias de branqueamento das elites brancas brasileiras foram fracassadas, embora permaneça no imaginário popular os critérios da do mito da democracia racial representada pelo grande percentual de pardos/as. Atualmente, nas regiões metropolitanas do Brasil, a população parda-preta é majoritária em: Belém (maior percentual de pardos), Salvador (a mais negra demográfica e culturalmente e com o crescimento dos pretos), Recife e Belo Horizonte, respectivamente, Norte, Nordeste e Sudeste $(\mathrm{BH})$, única nesta região, sendo que o Rio de Janeiro tem uma distância racial menor entre negros e brancos desta região (52\% brancos 
contra $48 \%$ de pardos e pretos) que São Paulo (60\% de brancos). Por outro lado, o Sul é branco onde Curitiba tem quase $80 \%$ de brancos e Porto Alegre com $80 \%$ é a mais branca em todo Brasil (PNAD/IBGE, 2006). Contudo, a divisão racial do espaço afirmado por Lélia Gonzales permanece no Brasil contemporâneo onde "O lugar natural do grupo branco dominante" (GONZALEZ e HASENBALG, 1982, p.15), continua.

Analisando a segregação urbana das duas maiores cidades brasileiras, Reinaldo de Oliveira (2013) afirma: "Compreendo que espaço e raça estão vinculados aos problemas da cidade"(OLIVEIRA, 2013, p.47) e das suas regiões metropolitanas onde “da senzala às favelas, cortiços, porões, invasões, alagados e conjuntos 'habitacionais' temos a permanência da "divisão racial do espaço." Ou, seja, a estrutura urbana de Norte ao Sul tem o mesmo padrão: os brancos e ricos vivendo em espaços valorizados (auto segregação) de um lado, e os pretos e pardos segregados nas periferias onde as políticas públicas não chegam, do outro. Cabe a pergunta de Reinaldo: Por que não há questionamentos sobre a ausência ou silêncio sobre o espaço urbano e raça? (OLIVEIRA, 2013, p. 47). A divisão racial do espaço afirmado por Lélia Gonzales permanece no Brasil contemporâneo onde os bairros brancos são os mais valorizados e ricos. Os bairros negros nas pequenas, médias e grandes cidades, e em particular, na cidade de Salvador, foram se constituindo em razão da história do trabalho escravo e da sociedade urbana industrial, por meio da expulsão e segregação dos negros e pobres nas periferias, territórios e lugares de menor valor no mercado imobiliário (CUNHA, 2019). Esta é uma questão fundamental no Brasil cada vez mais urbano e negro (fracasso das políticas de branqueamento) nossas pesquisas e análises não podem continuar ignorando a centralidade que deve ter o racismo, sexismo e classimo na produção das desigualdades sociorraciais e segregação racial e urbana e seu enfrentamento.

A metodologia da omissão das ciências e políticas públicas colonizadas tem sido uma estratégia bastante eficiente para não estudar a cidade patriarcal e racista e isso tem contribuído com a falta de prioridade e compreensão sobre a questão urbana, entrelaçada com as categorias gênero, raça classe e geração. Além disso, devemos ter estratégias acadêmicas e políticas na perspectiva de Milton Santos para quem o espaço: “(...) o espaço deve ser considerado como uma totalidade a exemplo da própria sociedade que lhe dá vida" (SANTOS, 1985, p.5).

Para Manuel Castells, um dos mais renomados estudiosos da questão urbana em prefácio ao livro "Alicia Ziccardi, Ciudades latinoamericanas: la cuestión social y la 
gobernanza local" com o título: De los movimientos sociales a la política urbana: La investigación indispensable de Alicia Ziccardi, afirma:

Numa época em que, mais uma vez, as cidades latino-americanas estão indignadas com suas condições de vida diante do cinismo e da corrupção das elites urbanas, é essencial ler e reler a obra de Alicia Ziccardi, porque foi ela, ao longo de uma distinta carreira acadêmica na Argentina, Brasil e México que, melhor do que qualquer outro estudioso do assunto, identificou a interação entre os movimentos reivindicatórios dos assentamentos populares e a formação de políticas urbanas. Apesar de prestar atenção aos projetos de mudança social que surgiram a partir do protesto social, ele não idealizou tais movimentos como novas formas revolucionárias que viriam para substituir as construções ideológicas de um proletariado de valor que mal era deu nessas latitudes - e que quando existiu era peronista (CASTELLS, 2020, p. 61).

A civilização capitalista-imperialista com séculos de atrocidades dentro e fora da Europa, passando pela violência colonial às duas guerras mundiais são provas cabais de que seus valores não contribuíram para um mundo mais justo, mais igualitário e fraterno, muito pelo contrário. Nesse cenário, para superação dos valores escravistas, racistas e patrimonialistas, partriarcais e sexistas, os desafios dos e das oprimidas de todo o mundo, é criar e/ou reforçar os instrumentos de transformação através das ciências, dos movimentos sociais antirracistas, anti sexistas, anticolonialistas, anti-homofóbicos e antilesbofóbicos e movimentos políticos mais amplos.

Assim, para a compreensão do problema racial no chamado Novo Mundo e suas interfaces com a formação das nossas sociedades, a formação da sociedade capitalista, o desenvolvimento das classes sociais e de suas implicações com a cristalização das raças, se faz necessário partir do debate histórico que se dá nas ciências em geral, principalmente as Ciências Sociais e suas interpretações coloniais e escravistas para a descolonização do saber e do poder.

$\mathrm{Na}$ contemporaneidade, o sistema capitalista e suas prioridades absolutas de mercado, de políticas neoliberais que destroem as conquistas da classe trabalhadora que empreendeu ao longo do tempo muitas lutas e negociações por um Estado de Bem Estar Social em países desenvolvidos, mas conseguido às custas dos países não desenvolvidos e não por acaso são os do chamado Novo Mundo com exceção dos EUA, que os substituíram em parte no pós-guerra, porém, de grande exploração da classe trabalhadora como é a lógica capitalista. 
No que diz respeito a atual fase do capitalismo global, Thomas Piketty (2013) mostra como a repartição das riquezas constitui um problema político fundamental para a estabilidade das sociedades democráticas modernas, e esta questão é muitas vezes discutida sem números precisos. O estudo é baseado numa compilação de variados dados históricos disponíveis, por exemplo, nos arquivos fiscais franceses. É um livro de economia que estuda a dinâmica da repartição dos rendimentos e da riqueza nos países desenvolvidos desde o século XVIII e tem uma enorme relevância para os estudos sobre as desigualdades socioespacial e sabemos que são principalmente sociorracial.

A riqueza que é produzida pela classe trabalhadora do mundo e a apropriação da mais-valia pela burguesia, onde as mulheres é a parte maior da superexploração pelo capital à medida que parte é trabalho não pago e outra mal paga. Isso quer dizer que o capitalismo global concentra riqueza de forma escandalosa e desafia todas as sociedades que buscam igualdade e democracia. A nossa "Democracia em Vertigem"5 e ameaças de golpe na América Latina é prova disso. O nosso continente vive em permanente sobressalto pelo histórico de golpes no passado e no presente pelos imperialistas de plantão.

Nossas estratégias de combate ao racismo e ao sexismo além da divisão de classes nas nossas sociedades passa pelo enfoque epistemológico de afro-centralidade em que os povos de África e sua diáspora devem ser o centro dos estudos e dos fenômenos sociais, ou seja, sejam protagonistas da sua própria história em todas as dimensões. Nessa perspectiva, destacamos os eventos históricos em que os povos africanos e afrodescendentes foram protagonistas da própria história, mas sempre invisibilizados, sobretudo em relação às mulheres negras. Desse modo, questionar as classificações sociais universais impostas pelo eurocentrismo no tempo e no espaço é fundamental para formação das nossas identidades e estratégias de superação do modelo de sociedade imposto pelo capitalismo desde sua acumulação primitiva até a contemporaneidade, onde o proletariado é cada vez mais inútil ao capital no capitalismo financeiro e proporciona maior exploração com um imenso exército de reserva, jamais visto.

\footnotetext{
${ }^{4}$ O Capital no século XXI (Le Capital au XXI e siècle) é um livro de economia escrito por Thomas Piketty e publicado pela primeira vez em França em 2013 pela editora Éditions du Seuil. Neste livro, o Autor estuda a dinâmica da repartição dos rendimentos e da riqueza nos países desenvolvidos desde o século XVIII.

${ }^{5} \mathrm{O}$ documentário de Petra Costa que concorreu ao Oscar e fez muito sucesso, trata da interrupção do mandato de Dilma Rousseff, do golpe de 2016, dos governos do PT, e mais uma vez um dos momentos mais dramáticos e turbulentos da História do Brasil.
} 
Portanto, a crise do capitalismo atual com as políticas neoliberais que tem provocado grandes concentração de renda e riqueza em poucas mãos, desigualdades urbanas expressas nas periferias, assim como a informalidade, o desemprego, a fome, a mobilidade espacial em várias escalas e $\operatorname{motivos}^{6}$ e mostra a complexidade do momento histórico que vivemos. Entretanto, apesar desse cenário, a direita e extrema direita tem avançado nas políticas neoliberais que tiram direitos, destroem o Estado de Bem Estar onde foi conquistado. Na América Latina o império americano continua apoiando e promovendo ataques a governos progressistas e socialistas para impor seus interesses imperialistas ${ }^{7}$. Ou seja, o capitalismo nunca deixou de ser selvagem.

O arsenal político, ideológico e econômico da classe dominante branca que trata as políticas públicas fundamentais como saúde, educação, alimentação, moradia decente, como gastos e usa a caridade para submissão total dos grupos mais vulneráveis socialmente, mas como vimos, somente através das lutas pretéritas e contemporâneas podememos derrotar a opressão de gênero, raça e classe.

\section{OS DESAFIOS CONTEMPORÂNEOS PARA A CONSTRUÇÃO DE SOCIEDADES-CIDADES IGUALITÁRIAS EM MÚLTIPLAS DIMENSÕES}

Ao contrário do que as narrativas eurocêntricas e falocêntricas propagam no seu imenso arsenal político-ideológico-cultural-econômico e epistemológico, as lutas libertárias negras e indígenas que ocorreram ao longo dos séculos de escravidão no chamado Novo Mundo, mostram que nossos ancestrais (homens e mulheres) contestaram a escravidão e buscaram alternativas. A Revolução Haitiana, ("Uma História Impensável” como analisa Michel-Rolph Trouillot, 1995, p.70), no século XVIII, levando à destruição da escravidão e à independência do Haiti, um momento decisivo na história do povo africano no chamado Novo Mundo é dos mais emblemáticos. De outro olhar "Sequência de eventos históricos ocorridos na antiga colônia francesa de Saint Domingue, atual Haiti

\footnotetext{
${ }^{6}$ Os dados da ONU revelam um drama crescente de refugiados/as em razão dos conflitos nacionais existentes em várias partes do mundo, seu aumento exponencial: em 2014, chegou a 59,5 milhões de pessoas, cerca de 22 milhões a mais em comparação com a década anterior e metade dos refugiados é menor de idade. A África concentra o maior número dos principais conflitos atuais e de refugiados/as. Pode-se imaginar o crescimento da crise humanitária com a Pandemia do Coronavirus com a indiferença como tratam estes grupos humanos especialmente a África por um racismo estrutural histórico e muitas vezes não declarado.

${ }^{7}$ O Brasil sofreu um golpe de Estado em 2016, onde foi derrubada a presidenta Dilma Rousseff, primeira mulher a governar o país, Venezuela continua sendo ameaçada, Cuba (bloqueio histórico), entre outros.
} 
na passagem entre os séculos XVIII e XIX e constitui o marco inicial da extinção da escravidão negra nas Américas" (LOPES, 2004, p.574). Antes, o Quilombo dos Palmares, no Brasil (século XVII, resistiu por mais de 100 anos), sendo, porém, destruído pelo império português.

A Revolta dos Búzios, final do século XVIII (1798-1799) ou Conjuração Baiana, também conhecida como Inconfidência Baiana, Revolta dos Búzios, na capitania da Bahia, no Brasil, para se libertar da Coroa Portuguesa, embora também derrotada foi fundamental nas lutas antiescravistas, e contribuíram com as lutas abolicionistas, durante o século XIX. A historiografia, contudo, ignora em grande medida estes e outros movimentos que tiveram grande contribuição às lutas libertárias antiescravistas e antirracistas protagonizadas pelos oprimidos e pelas oprimidas. A Inconfidência Mineira (1789-1792), ocorrida na Província de Minas Gerais, ao contrário da Conjuração Baiana é amplamente difundida, com feriado nacional no dia 21 de abril, e Tiradentes herói nacional cultuado, tendo suas imagens semelhantes à de Jesus Cristo. Reconhecimento justo, porém, é uma prova do racismo estrutural e institucional ao não tratar com o devido reconhecimento as lutas negras.

Por outro lado, a Revolução Francesa, em 1789-1799, mesmo período da Inconfidência Baiana e a Inconfidência Mineira (1789-1792) que foi um movimento liderado pela burguesia francesa é considerada como um dos mais importantes acontecimentos da história da Humanidade porque dela iniciou-se o processo de universalização dos direitos sociais e das liberdades individuais, previstos na Declaração dos Direitos do Homem e do Cidadão (e a mulher?) ${ }^{8}$. Além disso, implantou o republicanismo na Europa e a democracia representativa, fatos de muita relevância para as sociedades. Contraditoriamente, porém, os protagonistas destas conquistas, mantinham o processo escravocrata no chamado Novo Mundo e combatiam ferozmente as lutas negras e indígenas em processo etnocidas e genocidas das sociedades e suas culturas.

Durante a escravidão no "Novo Mundo" a organização de quilombos rurais ou urbanos foi uma das táticas muito utilizadas. De acordo com Clovis Moura, citando Edison Carneiro, as formas de lutas escravas se caracterizam pela tomada do poder que encontrou sua expressão nos levantes dos negros malês da Bahia (1807-1835), a

\footnotetext{
${ }^{8}$ Novas Abordagens no Ensino da Revolução Francesa: Inserção das temáticas de racismo e gênero por meio da obra de Olympe de Gouges. Livro publicado pelo NEAB-UFU no ano de 2012.
} 
insurreição armada, especialmente no caso de Manuel Balaio em 1839, no Maranhão e os quilombos tão bem exemplificados no Quilombo dos Palmares. Moura acrescenta as guerrilhas e a participação em movimentos que mesmo não sendo seus, adquirira novo conteúdo. "O quilombo foi, incontestavelmente, a unidade básica de resistência do escravo. Pequeno ou grande, estável ou de vida precária, em qualquer região em que existisse a escravidão lá se encontrava ele como elemento de desgaste do regime servil" (MOURA, 1988, p.103). O fenômeno do quilombismo espalhou-se pelas Américas onde hoje há descendentes de quilombolas que vivem em enclaves no Caribe, América Central e América do Sul. Costumavam refugiar-se em bosques e regiões pantanosas, então abundantes nas Américas. E faziam-no não apenas em busca da necessária proteção. Quilombolas estabelecidos próximos das cidades negras como Recife, Salvador e Rio de Janeiro, atuavam em várias atividades, inclusive comerciais. Quilombolas eram muito atuantes em todas as atividades, contudo, só mais recentemente têm sido reconhecidos a exemplo de Zeferina que em 1826, liderou a revolta do Quilombo do Urubu, no subúrbio de Salvador. Além disso, a influência dos povos negros e indígenas se organizavam de variadas formas e "Na primeira metade do século XX, vários estudos antropológicos sobre os impactos culturais nas Américas...” (MOREIRA, p. 14, 2006)

À luz das Epistemologias do Sul é que devemos analisar as os sujeitos sociais, buscando o resgate dos múltiplos significados de suas práticas coletivas a exemplo do quilombismo $^{9}$, abolicionismo, Ubuntu y Ubuntu criollo, das revoluções negras com destaque para as lutas feministas incorporando os feminismos negros, afro-latinos.

$\mathrm{Na}$ perspectiva de Abdias Nascimento: "Os quilombos são uma das primeiras experiências de liberdade nas Américas. Eles tinham uma estrutura comunitária baseada em valores culturais africanos. Sua organização política era democrática. Seu modelo econômico era o contrário do modelo colonial" 10

Milton Santos considera que

O espaço como uma instância da sociedade ao mesmo título que a instância econômica e a instância cultural-ideológica. Isso significa que, como instância ele contém e é contido pelas demais instâncias, assim como cada uma delas o contém e é por elas contida. A economia está no espaço, assim como o espaço está na economia. O mesmo se dá com o político-institucional e com o culturalideológico (SANTOS, 1985, p.1)

\footnotetext{
${ }^{9}$ No quilombo do Urubu Zeferina, liderou a revolta como grande guerreira.

${ }^{10}$ No $2^{\circ}$ Congresso de Cultura Negra das Américas (Panamá, 1980), Abdias apresenta sua tese do quilombismo. Ver IPEAFRO. Ipeafro.org.br.
} 
Ao discutir os desafios fundamentais para o futuro da África e suas diásporas, Maria Paula Meneses (2016) propõe pensar "de forma radical uma interculturalidade cosmopolita a partir da exigência de descolonização dos sabres e do sentido de ser" A descolonização dos saberes passa por exigir o direito à própria história e nessa perspectiva existem dois desafios principais: "um de natureza ontológica - a renegociação das definições do ser e dos seus sentidos - e, outro, epistémico, que contesta a compreensão exclusiva e imperial do conhecimento" (MENESES, 2016, p. 27-28).

Devemos como Frantz Fanon (2009), problematizar o carácter racial da epistemologia eurocêntrica, buscando as Epistemologias do Sul, como caminhos teóricosmetodológicos que possibilitam um diálogo intercultural, não hierárquico, que aponta para novos marcos civilizatórios e superação de relações hierárquicas e desiguais NorteSul como propõe Boaventura de Souza, por exemplo, ao questionar as teorias coloniais dominantes ou não.

Nesse sentido, a universalidade do sistema de dominação exige também explicações e práxis universais e particulares, numa relação dialética entre os povos oprimidos. Nesse contexto, a universalidade da dominação masculina também deve ser questionada não somente pelos estudos feministas que têm marcos teóricos fundamentados para uma nova epistemologia que coloca a mulher como sujeito da história e das Epistemologias do Sul. Nessa perspectiva vamos, a seguir refletir sobre os desafios coletivos do nosso devir, considerando "O movimento dialético entre forma e conteúdo, a que o espaço, soma dos dois, preside, é igualmente, o movimento dialético do todo social apreendido na e através da realidade geográfica” (SANTOS, 1985, p.2).

\section{ROMPENDO AS AMARRAS: FEMINISMO, FEMINISMO NEGRO E TERRITÓRIOS}

As mulheres africanas foram sequestradas e escravizadas no chamado Mundo Novo, nas últimas décadas do século XVI e tal como os homens negros sofreram com a violência colonial até o final do século XIX, quando as lutas abolicionistas aboliram a escravidão oficialmente. Nas senzalas, nos quilombos ou nas cidades constituíram formas diversas de resistência, participando também de todas as revoltas, revoluções, mas foram invisibilizadas pelas historiografias coloniais, burguesas-imperialistas, embora estudos 
recentes tenham trazido ao conhecimento mais amplo o protagonismo delas sistematicamente ignorado.

As sociedades burguesas constituídas com o paradigma colonial-escravista e patriarcal, diferenciaram o mundo da produção e o da reprodução. Na ordem burguesa o mundo da produção tornou-se dos homens e o da reprodução das mulheres, e entre outras questões fundamentais para entender o desenvolvimento capitalista e a ausência do recorte de gênero nos estudos, destacamos o trabalho feminino e a integração dos elementos sociais e econômicos em distintos períodos históricos, o que viabilizou a destruição das formas pretéritas da divisão social e espacial do trabalho, considerando-se que, antes da industrialização a família formava uma unidade produtiva onde seus membros, homens e mulheres e crianças produziam, isto é, trabalhavam. Foi com a implantação generalizada do modelo de produção capitalista que se iniciou a distinção entre as atividades de produção mercantil e atividades de subsistência, ou seja, trabalho remunerado (considerado produtivo) e trabalho doméstico considerado improdutivo (MATINEZ et al, 1995, p. 89).

Cabe ressaltar que as mulheres negras são pioneiras no mercado de trabalho, mesmo que informal, vendendo todo tipo de produtos em esquinas ou como ambulantes durante séculos e em feiras livres nas cidades pequenas, médias, grandes ou metrópoles atuais. Continuam sendo majoritárias nessa condição, assim como o trabalho doméstico e sustentam com sua força de trabalho não paga o capitalismo na sua fase financeira que destrói o trabalho e leva a classe trabalhadora ao desemprego e as mulheres com uma sobrecarga ainda maior. Contudo, não podemos esquecer que a força de trabalho não paga das mulheres em geral sustenta o capitalismo e sem mudanças na propriedade privada dos meios de produção a metade da população do planeta vai continuar a sustentar a acumulação de riqueza para os homens e brancos da classe dominante de uma forma mais perversa e bárbara do que com os homens brancos e negros da classe trabalhadora, sendo que os últimos são os mais explorados, principalmente nas Américas pela forma como foram formadas nossas sociedades.

Assim, as sociedades-cidades forjadas no chamado Novo Mundo sob a égide do colonialismo e escravismo, mostram que a discriminação contra a mulher no passado e no presente baseia- se no patriarcado, no racismo e na sociedade de classe capitalista como um conjunto de sistemas: econômico, sociocultural e simbólico, que precisa ser enfrentado em todas as suas dimensões visando a construção de novos marcos 
civilizatórios (SAFIOTTI, 1992, p.195). Para Ana Alice Costa:

A exclusão de gênero, assim como outras exclusões, por exemplo a de classe e a de raça, foram o elemento dominante no processo de formação da classe burguesa como elite emergente, interessada em afastar as velhas elites aristocráticas e garantir, assim, seu domínio sobre os estratos populares (COSTA, 1998, p.230).

Nesse contexto, devemos destacar que historicamente, o movimento feminista foi protagonizado pelas mulheres brancas desconhecendo que nós mulheres negras temos ascendência africana de mulheres que foram sequestradas pelo império colonial e toda a sua violência histórica e presente. Ou seja, nós mulheres negras, carregamos o peso das violências colonialista-escravistas em todas as suas dimensões e queremos romper com todas as visões e práticas coloniais e pós-coloniais. Contudo, ao longo do tempo-espaço, as afrofeministas, afrolatinas colocaram o dedo na ferida da "mulher universal" $\mathrm{e}$ reivindicam, propõem e constroem um feminismo negro, como aponta Sueli Carneiro:

\begin{abstract}
Nessa perspectiva, a luta das mulheres negras contra a opressão de gênero e raça vem projetando novos contornos para a ação política feminista e antirracista, enriquecendo tanto a discussão da questão racial quanto a questão de gênero. Esse novo olhar feminista e antirracista está integrado à tradição de luta dos movimentos negros, bem como o do movimento das mulheres, e afirma essa nova identidade política que resulta da condição específica de ser mulher e negra. $\mathrm{O}$ movimento atual das mulheres negras trazendo para o cenário político as contradições resultantes das variáveis raça, classe e gênero está movendo a síntese de bandeiras de luta que historicamente foram levantadas por movimentos e movimentos negros de mulheres do país, escurecendo por um lado as reivindicações feministas para torná-las mais representativas de toda a mulher brasileira, e, por outro lado, promovendo a feminização das propostas e reivindicações do movimento negro (CARNEIRO, 2017:111 )
\end{abstract}

Portanto, é necessário enegrecer os movimentos feministas em toda parte, é necessário que as Ciências Sociais deem centralidade à questão fundamental da opressão maior imposta às mulheres negras e indígenas, fortalecendo suas demandas e principais instrumentos de resistência ao sexismo e ao racismo frente às raças e classes dominantes. Trata-se de um movimento complexo, de busca da unidade na diversidade que envolve diferenças sociais, de classe, políticas, regionais, compreendendo que o colonialismo como espinha dorsal da sociabilidade moderna (capitalista) expõe as reificações presentes nas representações da civilização capitalista como expressão universal do gênero humano e o feminismo tem o dever de superar a lógica colonialista e pós-colonialista para a construção do novo projeto de sociedade. A descolonização do saber implica a crítica 
profunda a concepção humanista burguesa, de um lado, e o direito à própria história e a constituição das teorias afro feministas e antirracistas, anti-classistas, do outro, como instrumentos importantes para criação de novos paradigmas, nova cosmovisão, novas epistemologias, novas práticas que rompam com o processo de dominação em amplas dimensões.

Neste contexto, as epistemologias, os estudos feministas descoloniais do Sul elaboradas por afro feministas e feministas apontam outro referencial civilizatório nos aspectos culturais, religiosos, políticos, económicos e epistêmicos. Portanto, é importante que os movimentos sociais em geral e os feministas, em particular, não caiam nas armadilhas criadas pelo colonialismo e pós colonialismo, nos particularismos e avance na sua identidade historicamente negada e parafraseando o grito marxista pelo projeto de emacipação humana devemos buscar "Mulheres do Mundo Uni-Vos"! Trabalhadores e Trabalhadoras do Mundo, Karine Biseca, em “A Revolução será Feminista ou não Será: a pele da arte feminista descolonial”, aponta as várias possibilidades de transformação social na perspectiva das mulheres: africanas, palestinas, latino-americanas, caribenhas... Descolonizar o feminismo é também construir uma proposta global de transformação social, política, econômica, respeitando-se a diversidade em contraposição às experiências coloniais e pós-coloniais excludentes. Descolonizar as cidades e campos é preciso, enfrentado o racismo estrutural, o sexismo e classismo que estão na base das práticas públicas e privadas.

Nessa perspectiva, ainda que limitada, a Década Internacional Afrodescendente (2015- 2024) que tem como tema: "Afrodescendentes: reconhecimento, justiça e desenvolvimento", pode ser uma oportunidade tanto para questionar e combater todas as formas de racismo, discriminação racial, sexismo, xenofobia e qualquer tipo de intolerância relacionada, como para exigir dos governantes políticas públicas de promoção da igualdade de gênero e raça, criação e/ou funcionamento de instrumentos com enfoque de gênero-raça transversalisados em todas as políticas públicas.

Restam apenas 4 anos para acabar a década e se faz necessário uma avaliação do que já foi feito para propor avanços. Em geral existem, entretanto, o neofacismo tem imposto derrotas às políticas de igualdade de gênero, raça e classe, em muitos países do Norte e do Sul e o Brasil, particularmente, vive um momento dramático ao eleger um presidente, machista, racista, homofóbico, ou melhor, um neofascista que está desmontando todas as políticas públicas, acirrando as violações e o desrespeito aos 
direitos sociais, políticos, ambientais e econômicos, conquistados desde a derrubada da ditadura militar de 1964, aprovação da Constituição Cidadã de 1988, especialmente nos 13 anos de governo do Partido dos Trabalhadores - PT, quando políticas para mulheres, negros, indígenas, educação que incluiu estes segmentos, LGBTs, combate à fome, à exclusão dos historicamente excluídos de direitos fundamentais. Buscando romper o silenciamento sobre a África negada pela “democracia racial”, em 2003 o presidente Luiz Inácio da Silva, sancionou a Lei 10.639/03, para que o sistema educacional ensine a história e a cultura afro-brasileira e africana no Brasil. Já com 16 anos de vigência, esta grande conquista dos movimentos negros brasileiros, enfrenta enormes obstáculos na sua aplicação, especialmente nesse momento da nossa história, embora a determinação de muitas e muitos educadoras e educadores lutem cotidianamente para sua efetivação.

O sentimento que é descoberto no mundo hoje mantém algumas semelhanças com os cenários que o discurso colonial montado no tempo de Fanon. É como se o perigo minimalista das potências globais espreitasse cena nas metrópoles, e se aproximou tão rapidamente que diante de nossos olhos o zoom está se aproximando: o mundo é perigoso; a casa é perigosa e, finalmente, a mente capturada também é perigosa. A geografia do terror estreita, respira na parte de trás da cabeça (BIDASECA, p. 43, 2018).

Considero que ocorreram alguns avanços nas Ciências Sociais e políticas públicas no reconhecimento do racismo e sexismo como estruturantes das desigualdades socioespaciais, no entanto, a maioria dos estudos urbanos não tornaram a cidade sexista e racista como objeto de estudo e nem as políticas públicas urbanas. Com efeito, esta omissão joga na invisibilidade e na cidadania de segunda classe a grande maioria das pessoas que constroem a cidade e não gozam dos direitos mais fundamentais (GARCIA, 2013, p.101).

\section{CONCLUSÃO}

Nesse artigo tentamos de um lado, refletir sobre a sociedade colonial-escravista, estruturada na tríade senhores de escravos brancos de origem europeia, escravos/as negros/as de origem africana e ameríndios deslocados dos seus territórios de origem ou exterminados, que permeia nossa história. Compreendo, como autoras e autores com os quais dialogo nesse artigo, que a gênese do chamado Novo Mundo tem seu tripé no colonialismo-escravismo, patriarcalismo-racismo e no mercantilismo-capitalismo, que moldou as sociedades nas Américas, negando todas as organizações pretéritas das 
sociedades indígenas e negras em seus territórios exige de todas as pessoas propor e construir novos projetos civilizatórios.

A construção eurocêntrica das sociedades e cidades no chamado Novo Mundo, também produziu modelos explicativos que alimentam até hoje uma perversa engrenagem teórico- ideológica que favorece a reprodução de desigualdades e a perpetuação no poder dos grupos brancos hegemônicos. "A este modelo interessa a omissão da simbiose patriarcado-racismo-capitalismo que engendra a discriminação da mulher e que o patriarcado e o capitalismo, sendo o sistema político e econômico não podem ser vistos isoladamente, pois é um sistema de dominação com "faces distintas do mesmo modo de produzir e reproduzir a vida" (SAFFIOTI apud COSTA 1998, p.39-40).

Assim, sexismo e racismo ao hierarquizar os indivíduos segundo atributos físicos em superiores e inferiores, estruturam os modos de vida e são determinantes na formação sócio-histórica em todas as sociedades. Nesse sentido, a ideia de raça tem sido eficaz para manter a dominação multissecular no chamado Novo Mundo, assim como "patriarcadoracismo-capitalismo" em manter a mulher subalterna, especialmente as afrolatinoamericanas, afroamericanas, indígenas e caribenhas. Portanto, uma análise sobre o fenômeno do sexismo e racismo, fenômenos universais, construídos historicamente, impõe muitos desafios teóricos-metodológicos e políticos.

Por outro lado, buscamos compreender a relevância dos movimentos sociais em geral e os movimentos negros e afrofeministas, históricos e contemporâneos e em particular, a partir da história de África (origem da humanidade), que cria as possibilidades de diálogo intercultural e a descolonização do saber estratégico para as lutas populares contra todas as formas de opressão e a filosofia africana como um referencial fundamental:

Ubuntu é a raiz da filosofia africana. A existência do africano no universo é inseparavelmente ancorada sobre ubuntu. Semelhantemente, a árvore de conhecimento africano deriva do ubuntu com o qual é conectado indivisivelmente. Ubuntu é, então, como uma fonte fluindo ontologia e epistemologia africana. Se estas últimas forem as bases da filosofia, então a filosofia africana pode ser estabelecida em e através do ubuntu. Nosso ponto de partida é que ubuntu pode visto como base da filosofia africana (RAMOSE, 1999, 1).

Assim, as teorias feministas e antirracistas, são instrumentos importantes para criação de novos paradigmas, novas epistemologias, novas práticas que rompam com o processo de dominação de gênero, raça e classe social. As teorias feministas e antirracistas, 
são instrumentos importantes para criação de novos paradigmas, novas epistemologias, novas práticas que rompam com o processo de dominação.

Nessa perspectiva, "Construyendo las Epistemologías del Sur: para un pensamiento alternativo" proposto por Boaventura de Souza Santos (2018), e os aportes dos feminismos, especialmente dos feminismos negros é o caminho para a constituição de projetos estratégicos em todas as lutas libertárias contemporâneas.

A questão racial-étnica e de gênero são fundamentais para os estudos e práxis descoloniais nas perspectivas afrofeministas, afrocaribenhas, afrolatinas, etc. Para a materialização de tudo que refletimos neste artigo, é o fortalecimento das experiências contemporâneas dos movimentos negros, movimentos afrofeministas, feministas, Ubutun, Ubutum Criolo para construção de um mundo novo, de um humanismo novo, de práticas libertadoras de todas as amarras coloniais e pós-coloniais impostas historicamente aos povos negros e indígenas principalmente que deve ser nosso objetivo.

Por fim, reafirmar, à luz do que refletimos neste artigo, que as lutas na atual fase do capitalismo globalizado, igualmente racista e sexista exige um anticolonialismo, antiimperialismo, anti-nacionalismos e antifundamentalismo, e unidade na diversidade, a partir de uma pedagogia dos povos oprimidos.

\section{REFERÊNCIAS BIBLIOGRÁFICAS}

BIDASECA, Karina, La amnesia del imperio: los muros del racismo, el apartheid y el ancho mar de las estrellas. Ciudad Autónoma de Buenos Aires: SB, 2018.

CARNEIRO, Sueli, Enegrecer o feminismo. In: Más allá del decenio de los pueblos afrodescendientes / Rosa Campoalegre Septien ... [et al.]; editado por Rosa Campoalegre Septien; Karina Andrea Bidaseca. - 1a ed. - Ciudad Autónoma de Buenos Aires: CLACSO, 2017.

CASTELLS, Manuel. De los movimientos sociales a la política urbana: La investigación indispensable de Alicia Ziccardi. In: Ciudades latinoamericanas. La cuestión social y la gobernanza local. Ziccardi, Alicia compilado por María Mercedes Di Virgilio; prólogo de Manuel Castells. - 1a ed. - Ciudad Autónoma de Buenos Aires: CLACSO, 2020.

COSTA, Ana Alice A. As donas no poder: mulher e política na Bahia. Coleção Baianas/NEIM/FFCH/UFBA, Salvador, 1998.

JUNIOR, Henrique Cunha. Bairros Negros: a foruma urbana das populações negras no Brasil. Revista da Associação Brasileira de Pesquisadores Negros (ABPN), v. 11. Número especial, p.6586, maio 2019. ISSN 2177-2770. Disponível em: <https://abpnrevista.org.br/index.php/site/article/view/683 >. Acesso em: 10 abril. 2020

FANON, Frantz. "La experiencia vivida del negro” em Piel negra, máscaras blancas. Madrid: 
Akal, 2009.

GARCIA, Antonia dos Santos. Relações de gênero, raça e classe na cidade d'Oxum: o caso do Subúrbio Ferroviário de Salvador. In: Relações de Gênero, Raça, Classe e Identidade no Brasil e na França. Rio de Janeiro, Letra Capital, 2013.

GARCIA, Antonia. As mulheres da cidade d'Oxum: relações de gênero, raça e classe e organização do movimento de bairro em Salvador. Salvador. EDUFBA, 2006.

GARCIA, Antonia. Desigualdades raciais e segregação urbana em antigas capitais: Salvador, cidade d'Oxum e Rio de Janeiro, cidade de Ogum. Rio de Janeiro, Garamond, 2009.

GONZALEZ, Lélia, HASSENBALG, Carlos. O Lugar de Negro. Marco Zero. Rio de Janeiro, 1982.

HASENBALG, Carlos. Notas sobre relações de raça no Brasil e na América Latina. Rio de Janeiro IUPERJ, 1992.

IANNI, Octavio. Escravidão e racismo. Hucitec: São Paulo, 1988

IANNI, Octavio. Karl Marx: sociologia. Ática: São Paulo, 1979.

IANNI, Octavio. Raças e classes sociais no Brasil. São Paulo: Brasiliense, 1987.

KOSIK, K. Dialética do concreto. Paz e Terra, Rio de Janeiro, 1976.

MARTINEZ, Ana, S, MOYA, Juana, M. R. \& MUÑOZ, Maria. A. D. Mujeres, espacio y sociedad: Hacia una Geografia de Género. Sintesis, Madrid, 1995.

MENESES, Maria Paula. "A questão negra entre continentes”: possibilidades de tradução intercultural a partir das práticas de luta? Sociologias, Porto Alegre, ano 18, no 43, set/dez 2016, p. 176-206.

MOREIRA, Carlos Eduardo. Cidades Negras: africanos, crioulos e espaços urbanos no Brasil. Alameda, São Paulo, 2006.

MUNANGA, Kabengele. Uma abordagem conceitual das noções de raça, racismo, identidade e etnia. In: BRANDÃO, André Augusto (Org). Programa de Educação sobre o Negro na Sociedade Brasileira. Niterói, EDUFF, 2004.

OLIVEIRA, Reinaldo José de. A cidade e o negro no Brasil. Alameda, São Paulo, 2013.

ORGANIZAÇÃO DAS NAÇÕES UNIDAS. 90\% da Populacão Mundial tem Preconceitocontra-as-Mulheres. Disponível em e acesso em 06/03/2020: https://www.cartacapital.com.br/sociedade/90-da-populacao-mundial-tem-preconceito-contraas-mulheres-diz-onu/

PIKETTY, Thomas. Le Capital au XXI e siècle. Éditions du Seuil, França, 2013

QUIJANO, Anibal. Colonialidade do poder, eurocentrismo e América Latina. CLACSO, Consejo Latinoamericano de Ciencias Sociales, Buenos Aires, 2005

QUILOMBOS DAS AMÉRICAS: articulação de comunidades afrorrurais: documento síntese. Brasília: IPEA: $\quad$ SEPPIR, 2012. 79 p: gráfs., tabs. fots. 
RAMOSE, Mogobe B. African Philosophy through Ubuntu. Harare: Mond Books, 1999, p. 4966. Tradução Arnaldo Vasconcellos.

SANTOS, Boaventura, de Sousa. Construyendo las Epistemologías del Sur: para un pensamiento alternativo. Paula Meneses ... [et al.]. - 1a ed . - Ciudad Autónoma de Buenos Aires: CLACSO, 2018.

SANTOS, Milton. Espaço e método. Nobel: São Paulo,1985

Por uma outra globalização. Record, São Paulo: 2000

SCHUMAHER, Schuma e VITAL BRASIL, Erico. Mulheres Negras do Brasil. Senac

TROUILLOT, Michel-Rolph. Una historia impensable: la revolución haitiana como un no evento" en Silencing the Past. Pawer an the Production of History, Boston: Beacon Pres, 1995, págs.70-107.

Recebido em: 22/09/2020

Aceito em: 30/10/2020 